\title{
TWO CASES OF PARINAUD'S CONJUNCTIVITIS
}

\author{
BY
}

\author{
DR. C. D. Verryp and DR. K. T. A. Halbertsma \\ LEIDEN \\ DELFT
}

THE fact that, under the name of Parinaud's conjunctivitis, various conditions caused by different micro-organisms have been described by several observers shows that the disease is not sufficiently well defined. It is necessary to differentiate between the disease as originally described by Parinaud ${ }^{(1)}$ and other similar conditions. In the original syndrome the three cardinal symptoms were : (1) unilateral swelling with granular formation of the palpebral conjunctiva; (2) swelling of the praeauricular and submaxillary glands of the same side; (3) fever. Pascheff( ${ }^{(2)}$ described a series of cases under the name of "conjunctivitis necroticans infectiosus" in which unilateral disease of the conjunctiva was accompanied by glandular swelling and fever but in which, as he pointed out, the conjunctival condition differed from that described by Parinaud since, in his cases, ulceration and necrosis were marked features. He isolated a Gram-negative bacillus which he termed the micro-bacillus polymorphus necroticans.

Guinea-pigs inoculated with this bacillus died within a few days with enlarged spleens containing necrotic areas similar to those observed in the human eyelid. Pascheff points out that the organism responsible for Parinaud's disease is not pathogenic for guinea-pigs. For this reason he considers his cases as belonging to a different type and also rejects the cases described by Bayer and von Herrenschwand ${ }^{(3)}$ as due to the bacillus pseudo-tuberculosis rodentium (also pathogenic for guinea-pigs in 6-12 days) on the same account. Rolandi(4), reviewing 111 cases from the literature, concludes that Parinaud's disease is not a distinct entity but rather a clinical syndrome; the classical form a special form of conjunctival tuberculosis. Morax ${ }^{(5)}$ considers that Parinaud's disease has nothing to do with tuberculosis since there is no resemblance in the clinical symptoms nor in the pathological anatomy, and more particularly on account of the negative results of inoculation in animals. Verhoeff( ${ }^{(6)}$ has observed a large number of cases which he considers to be typical instances of the disease. In all of his cases but one he found, using a modified Gram staining, filaments of a leptothrix which he believes to be the cause, and named the disease "Leptothricosis Conjunctivae." The leptothrix was chiefly present in areas of cell-necrosis situated in the superficial layers of the conjunctiva. No ulceration was observed, and all animal inoculations gave negative results.

Our cases, the description of which follows, clinically and histologically mostly resembled those published by Verhoeff. 
Bacteriological examination failed to show any causative microorganism.

Case 1 (Figs. 1 and 2). This case was shown at the Dutch Ophthalmological Society (7). The patient was a boy, aged 16 years, of Austrian nationality who was first seen at the Leiden University in September, 1925. He had suffered for a fortnight from redness of the right eye and swelling of the right cheek. He was otherwise in good health. He had previously had mumps, mainly on the right side. On examination the lower eyelid on the right side was swollen and the ocular conjunctiva injected. The lower fornix was covered by reddish semi-transparent granulations with an uneven surface. Some defects of this surface were stainable but there was no definite ulceration. Some mucous secretion was present. The upper eyelid showed no pathological change and the cornea wạs normal. The iris, lens, and fundus were all healthy. The visual acuity of both eyes was $10 / 10$. The left eye was normal in every respect. The right parotid gland was swollen. Under the ear the tumour was rather firm and not very painful. Under the lower jaw the swelling was more dough-like and more tender to palpation. There was no fluctuation. The submaxillary gland was also swollen, and the body temperature was raised to about $39^{\circ} \mathrm{C}$. The liver was enlarged, as tested by percussion, but not palpabje. The spleen was distinctly palpable and protruded about two inches below the costal margin. The blood-reaction as regards syphilis was negative. The haemoglobin index (Sahli), as also the erythrocyte and leucocyte counts were normal. The increase of the eosinophile cells observed by Weaver, Rolandi, and Sanford Gifford ${ }^{(8)}$ was not found in our patient. There was, however, as noted by Pascheff in his cases of necrosing conjunctivitis, a decrease of polynuclear leucocytes (30 to 40 per cent.), associated with the presence of numerous lymphocytes (45 per cent.). The blood condition remained unaltered for some weeks. The conjunctival secretion contained only the staphylococcus albus. Some of the granulation tissue was excised and submitted to bacteriological and histological examination.

Bacteriological examination.-Cultures on Sabouraud plates remained sterile, thus excluding any sporotrichosis. Inoculations in guinea-pigs, both subcutaneous and intraperitoneal, and also subconjunctival in rabbits and monkeys, were made with an emulsion of the tissue. No reaction was observed in any of the animals even after several months. In the course of the disease a small praeauricular gland broke down and the purulent matter was investigated in the same way and with the same negative result. Cultures from the pus on agar and broth remained sterile. Ziehl-Neelsen staining was negative; no Much granules were present. 


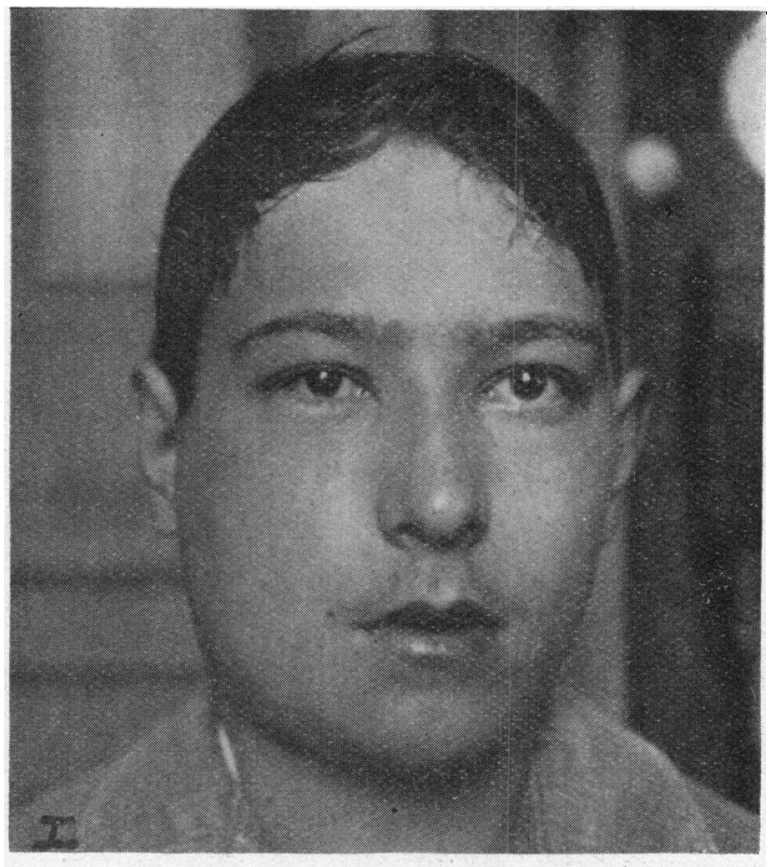

FIG. 1 .

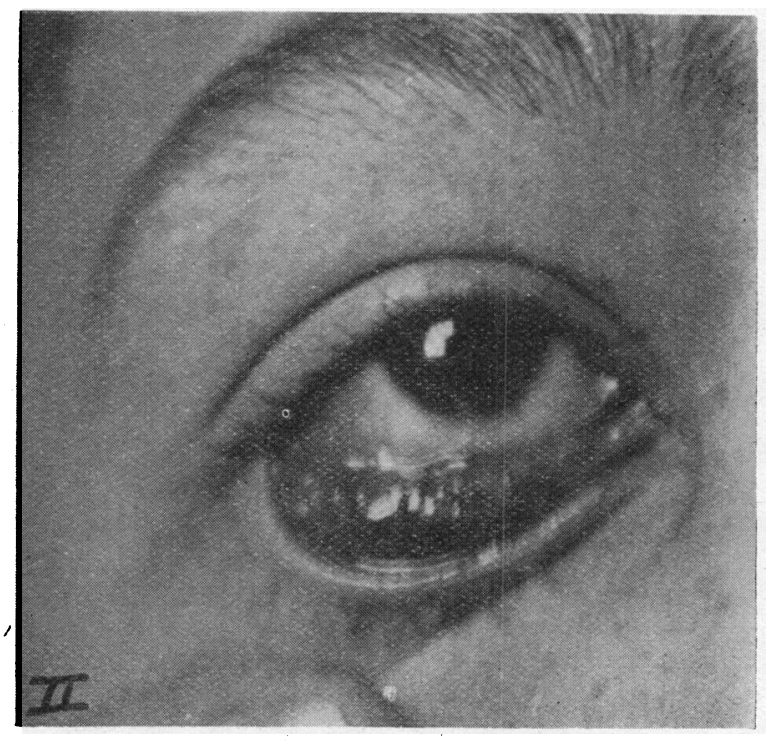

FIG, 2, 
Histological examination.-The conjunctival epithelium was not much altered with the exception of defective staining of the nuclei. Immediately beneath the epithelium there was a layer containing many fibroblasts and small blood and lymph vessels filled with lymphocytes. In the deeper layers infiltrations of lymphocytes, and polynuclear leucocytes were observed. These layers a!so contained some plasma cells. These cellular collections were mostly diffuse but were in some places grouped in greater density. The appearances agreed with the description of Morax, and correspond with the atypical proliferative inflammation characteristic of infectious granulomata. There were also present areas of cellnecrosis of the type described by Verhoeff. Examination by the modified Gram method described by that author revealed no leptothrix. Ziehl-Neelsen staining also gave a negative result. Old tuberculin (Koch) was injected after the patient's temperature had fallen to normal, but produced no reaction either general or local.

The subsequent course of the disease was as follows: the temperature after remaining elevated for a few days fell to normal at the end of a week. The conjunctival and glandular condition improved together. At the end of a month the conjunctiva was still somewhat swollen and red, the parotid was no longer palpable though the submaxillary gland was still a little enlarged. The blood condition was unaltered, and the spleen was still enlarged. Five months later the submaxillary gland was still palpable, and the spleen a little enlarged; the latter had rather a firm consistence.

Case 2. Miss X-., aged 23 years, has had the right eye inflamed for a fortnight. Swelling of the eyelids and redness of the conjunctiva had started suddenly without any known cause. There had been no previous illness or affection of the eye, neither had there been any animal contact. On examination the right upper eyelid was much more swollen than the lower one. The skin of the upper lid was of a bluish tinge, and the ocular conjunctiva was slightly injected. The inner side of the lower lid was redder than usual but showed no other change. The tarsal conjunctiva of the upper lid was covered by a granular mass with a smooth surface without any visible ulceration. The granulations were transparent and of a yellowish colour, and extended from the margin of the lid to the superior fornix. They were arranged parallel to the fornix and were covered by a superficial vascular network. The amount of conjunctival secretion was moderate and contained no typical micro-organisms. The visual acuity of both eyes was $10 / 10$ without glasses and the fundi were normal. The right praeauricular and submaxillary glands were enlarged and the former was tender on pressure. The right side 
Parinaud's Conjunctivitis

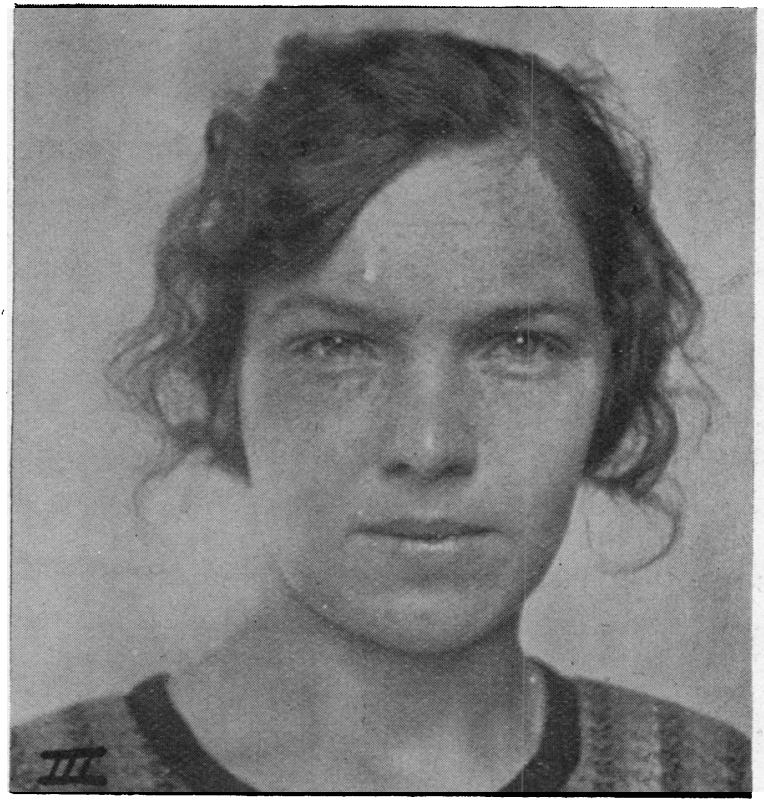

FIG. 3.

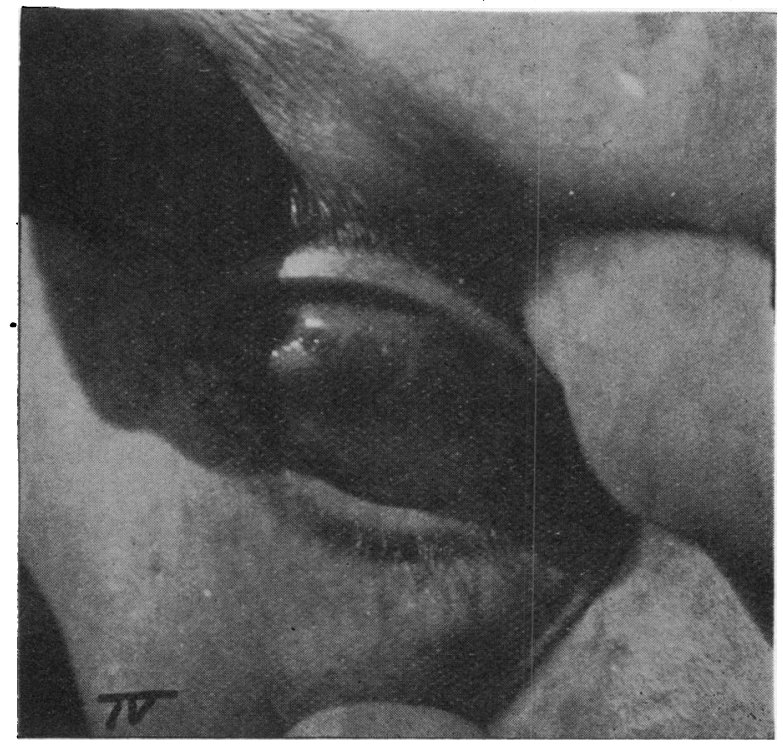

FIG. 4.

을. 
of the face gave the impression of being oedematous. The temperature was $38.3^{\circ} \mathrm{C}$. The blood Wassermann reaction was negative and the urine was normal. The blood pressure was raised (max. 170, min. 85) and the spleen was enlarged to palpation. The haemoglobin index (Sahli) was 66 , the number of leucocytes 9,400 ; the number and shape of the rest of the blood corpuscles was normal. Leucocytes, 78 per cent. polynuclear, 8 per cent. mononuclear, 14 per cent. lymphocytes. The leucocytes occasionally contained some toxic granules.

A piece of the granulation tissue was excised and investigated at the Pathological Institute of the Leiden University. The epithelium showed no change. In the superficial layers there were many necrotic areas surrounded by numerous lymphocytes and plasma cells. In the deeper layers there was much granulation tissue. No micro-organisms were found in the sections and Verhoeff's staining method revealed no leptothrices. Inoculations of the granulation tissue in the groin and peritoneum of the guinea-pig produced no reaction after five months.

Iodoform ointment ( 5 per cent.) was applied to the eye daily for a few weeks. The swelling of the upper lid and of the glands decreased slowly, and the fever, which at the beginning was fairly constant, disappeared. After two months from the start the aspect of the eye was normal again and the excised parts of conjunctiva had quickly healed.

Summary.-The cases here described show clinically the same aspect : relatively acute onset of the disease; involvement of the homolateral glands synchronous with the changes in the eve; elevation of temperature; enlargement of spleen; and similar appearance of the conjunctiva. The only difference was in the blood condition. The glandular swelling persisted for a considerably longer period than the changes in the eye. The histological examination in both cases gave results closely resembling those found by Morax and Verhoeff. The bacteriological examination failed to show anv causative micro-organism. It is certainly very improbable that the tubercle bacillus should be responsible for the disease. We consider that both patients suffered from the typical conjunctivitis of Parinaud.

\section{REFERENCES}

1. Parinaud.-Soc. d'Ophtal. de Paris, 1889

2. Pascheff.-Arch. d'Ophtal., Vol. XXXVIII, pp. 23 and 83, 1921.

3. Bayer and v. Herrenschwand. - Arch. f. Ophthal., Vol. XCVIII, p. 342, 1919.

4. Rolandi.-Ophthalmic Year Book, p. 113, 1916.

5. Morax.-Pathologie Oculaire, p. 102, 1921.

6. Verhoeff.-Amer.Jl. of Ophthal., p. 705, 1918.

7. Verryp.-Ned. Tydschr. v. Geneesk., p. 1602, 1926.

8. Sanford Gifford.-A mer. Jl. of Ophthal., p. 450, 1925. 